Conf $950927--4$

UCRL-JC-120469

PREPRINT

\title{
Computational Fluid Dynamics Modeling for Emergency Preparedness \& Response
}

\author{
R.L. Lee \\ J.R. Albritton \\ D.L. Ermak \\ J. Kim
}

This paper was prepared for submittal to the

International Conference \& Workshop on Modeling \& Mitigating

New Orleans, LA

September 26-29, 1995

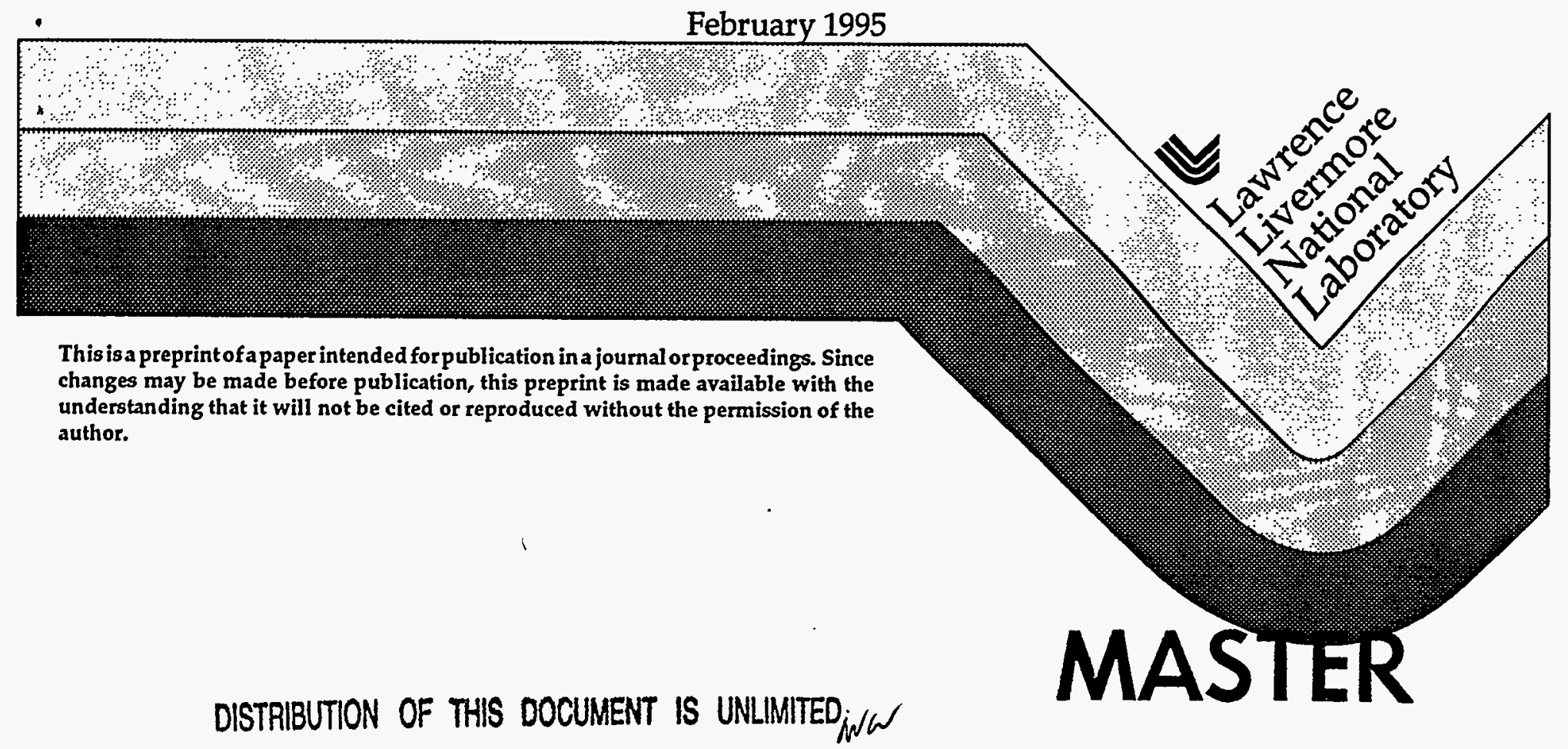




\section{DISCLAIMER}

This report was prepared as an account of work sponsored by an agency of the United States Government. Neither the United States Government nor any agency thereof, nor any of their employees, make any warranty, express or implied, or assumes any legal liability or responsibility for the accuracy, completeness, or usefulness of any information, apparatus, product, or process disclosed, or represents that its use would not infringe privately owned rights. Reference herein to any specific commercial product, process, or service by trade name, trademark, manufacturer, or otherwise does not necessarily constitute or imply its endorsement, recommendation, or favoring by the United States Government or any agency thereof. The views and opinions of authors expressed herein do not necessarily state or reflect those of the United States Government or any agency thereof. 


\section{DISCLAIMER}

Portions of this document may be illegible in electronic image products. Images are produced from the best available original document. 


\title{
Computational Fluid Dynamics Modeling for Emergency Preparedness and Response
}

\author{
R. L. LEE, J. R. ALBRITTON, D. L. ERMAK and J. KIM \\ Lawrence Livermore National Laboratory \\ Livermore, CA 94551
}

\section{INTRODUCTION}

Computational fluid dynamics (CFD) has played an increasing role in the improvement of atmospheric dispersion modeling. This is because many dispersion models are now driven by meteorological fields generated from CFD models or, in numerical weather prediction's terminology, prognostic models. Whereas most dispersion models typically involve one or a few scalar, uncoupled equations, the prognostic equations are a set of highly-coupled, nonlinear equations whose solution requires a significant level of computational power. Until recently, such computer power could be found only in CRAY-class supercomputers. Recent advances in computer hardware and software have enabled modestly-priced, high performance, workstations to exhibit the equivalent computation power of some mainframes. Thus desktop-class machines that were limited to performing dispersion calculations driven by diagnostic wind fields may now be used to calculate complex flows using prognostic CFD models.

The Atmospheric Release and Advisory Capability (ARAC) program (Sullivan, et al., 1993) at Lawrence Livermore National Laboratory (LLNL) has, for the past several years, taken advantage of the improvements in hardware technology to develop a national emergency response capability based on executing diagnostic models on workstations (figure 1). Diagnostic models that provide wind fields are, in general, simple to implement, robust and require minimal time for execution. Such models have been the cornerstones of the ARAC operational system for the past ten years. Kamada (1992) provides a review of diagnostic models and their applications to dispersion problems. However, because these models typically contain little physics beyond massconservation, their performance is extremely sensitive to the quantity and quality of input meteorological data and, in spite of their utility, can be applied with confidence to only modestly complex flows.

In anticipation of the next generation of response activities, we are now embarking on a development program to incorporate prognostic models to generate, in real-time, the meteorological fields for the dispersion models. In contrast to diagnostic models, prognostic models are physically-based and are capable of incorporating many physical processes to treat highly complex flow scenarios. Furthermore these models require minimal atmospheric data as input and can generate a variety of relevant meteorological information as by-products. A few workstation-based prognostic models have been used routinely for (non-real-time) emergency preparedness situations and, to a limited extent, operational weather forecasting. 
While we have been successful in employing workstation-based diagnostic models for realtime emergency responses, the computational demands on prognostic modeling in real-time are significant. Prognostic response models require both improvements in numerical algorithms as well as hardware processing speed to become feasible. We believe that prognostic models, with the capability of responding to real-time emergencies, can be developed by combinating good physics submodels and efficient, well-designed, numerical schemes that exploit the parallel (or massively-parallel) processing architecture of the latest machines.

\section{COMPUTATIONAL FLUD DYNAMICS ON WORKSTATIONS}

High-performance workstations are now widely-used as computational engines for research and development in fluid dynamics. There are several factors that led to the explosive use of such machines for even very computationally-intensive CFD simulations. First, and perhaps foremost, is the sharp decrease in cost as well as the increase in processing power of new machines. New workstations with central processing units such as those found in the DEC/ALPHA or the SGI/R8000 now perform mathematical operations with 64-bit precision, an accuracy that was exclusively . available on CRAY-class supercomputers. The gradual standardization and almost universal adoption of the UNIX operating system has established a distributed computational platform whereby different computer architectures ranging from supercomputers to minicomputers can instantly share information and codes from remote locations.

Prognostic models requiring meteorological data for forecasts have benefitted greatly from the establishment of the information highway that provides timely access to observational and forecast data from major data centers located nationally and internationally. For example, National Weather Service (NMC) meteorological analyses and forecasts at $80 \mathrm{~km}$ horizontal resolution globally and shortly at $30 \mathrm{~km}$ resolution over the continental U. S. are available to the public via the INTERNET. Global forecasts from European agencies (e.g., ECMWF) also can be accessed via this network. Besides being the number-crunching engines for CFD calculations, many of the same workstations are routinely used as high performance graphics machines for the postprocessing of the vast amount of data that emulate from these CFD models.

On the software side, numerical techniques that enhance the computational efficiency and accuracy of the models are constantly being developed. Many prognostic models now incorporate some form of nesting procedure to imbed smaller, but higher resolution, domains within the computational domain of interest in order to minimize grid and memory requirements. Recent advances in numerical treatments of open boundaries have also contributed to more efficient employment of computational domains resulting in further reduction of grid requirements.

Finally, breakthroughs in workstation productivity such as the new machines that deploy parallel or massively-parallel architecture will significantly reduce the wallclock time of computations and enhance the feasibility of workstations for real-time applications. We expect that real-time forecasts, at resolutions of 20 to $30 \mathrm{~km}$ with multiply-nested domains down to 1 to $5 \mathrm{~km}$, will be achievable on workstations within the next few years. 


\section{APPLICATIONS OF CFD TO EMERGENCY PREPAREDNESS AND RESPONSES}

The traditional role of CFD models is to supply wind fields as input into the dispersion models. Typical examples of the meteorological data that dispersion models require are velocity fields and characterizations of the atmospheric thermal stability Since emergencies can occur at any geographic location and at any scale, it is impractical to develop a single CFD model that can treat problems over all scales. For example, the Chernobyl accident in 1986 involved dispersion of radioactivity on a global scale whereas the Three-Mile Island nuclear powerplant accident affected only a limited area within tens of kilometers from the site.

Most CFD models are loosely classified under two major groups, based on scale considerations. Hydrostatic models apply to flows on regional or global scales, and nonhydrostatic models are used for local flows or flows requiring detailed simulations of very fine-scale phenomena (e.g., physics of clouds or interaction of turbulent eddies): Within each of the two groups one can further divide the models into subclasses in which various physical simplifications can be invoked to generate special models for specific applications.

Typically, general circulation or hemispheric models are used for computing meteorological fields on global scales whereas limited-area (or mesoscale) models are used for regional and local scale forecasts. ARAC has responded to several emergencies that required the use of global forecast data. Of the recent events, the more prominent of these were:

- The radioactive plume released from the Chernobyl accident

- The Kuwait oil fires involving releases of multiple smoke plumes

- Tracking of the ash plume generated by the eruption of Mt. Pinatubo

In all of the above cases, the wind fields were obtained from global forecast models.

Our CFD models have also been applied to a variety of local-scale $(1 \mathrm{~km}-100 \mathrm{~km})$ accidental release scenarios. Some examples are:

- Accidental and planned releases over complex terrain

- Releases from and/or around buildings

- Releases of denser-that-air gases or aerosols

In all of the above cases the terrain, building or the released material itself significantly impacts the dispersion of the pollutants within the flow field. The release durations for the local cases 
are usually short (over a few hours at most), therefore it is generally assumed that inflow boundary conditions are "static" (time-independent) and diurnal effects are negligible.

\section{NEW APPLICATIONS OF CFD ON REGIONAL SCALES}

While most of the CFD applications to date have been focused on generation of wind fields as input to dispersion models for assessment or emergency preparedness purposes, we are beginning to explore our utilization of prognostic models in weather-related emergencies. Forecast precipitation and temperature fields over California during the flood-related precipitations of the recent winter months have demonstrated the usefulness of these models in generating information beyond that of wind fields. Prognostic models forecasting on regional scales will play an important role in advising local agencies in emergency planning for severe weather scenarios.

In addition, model output information such as precipitation (rain or snow), moisture, temperature and surface moisture are often necessary for predicting the fate of pollutants under more complex meteorological conditions. For example, wet scavenging during precipitation is an important sink of airborne pollutants leading to the premature deposition of the contaminants. Likewise, the dispersion pattern of surface emissions can be changed by the stabilizing influence of a ground-based fog layer.

Workstation-based mesoscale models have recently been used to provide real-time forecasts on regional scales for emergency response to locally-induced severe weather. In "Regional Response Forecasting," meteorological forecasts of 3 to 48 hours are generated continuously with nested grid resolutions of 1 to $20 \mathrm{~km}$ centered at a specific site of interest. These locallygenerated forecasts are available for dispersion calculations or for dissemination to local and government agencies. This local-scale operational forecasting procedure has been used to predict convective storms that can impact launch operations at the Kennedy Space Center.

Several other potential emergency preparedness or response applications of regional scale prognostic models are:

- Fire hazard warning - requiring prediction of air temperature, wind speed and moisture conditions. for fire prevention

- Flood hazard warning - precipitation forecasts in conjunction with hydrological models for prediction of potential flood conditions

- Localized severe weather warning - thunderstorms, tornados, duststorms, etc.

Many of these weather-influenced emergencies are currently predicted, if at all, on relatively coarse grid resolutions via continental-scale operational weather forecast models using supercomputers. We anticipate that these operations will be replaced by local weather forecast centers operated by a small meteorological staff using clusters of high-performance workstations. 


\section{GROUPS ACTIVE IN DEVELOPING CFD MODELS ON WORKSTATIONS FOR EMERGENCY PREPAREDNESS/RESPONSE APPLICATIONS}

Over the past few years, there has been a proliferation of work on the development of multiple platform workstation-based CFD models, primarily in the engineering fields. There are several groups, including LLNL, who have been active in developing such models for emergency preparedness and responses. The following is a selected list of the groups and the models that are under development for such applications:

ARPS

The Advanced Regional Prediction System (ARPS) is a widely-used prognostic model for numerical prediction of regional-scale weather. The National Severe Storms Laboratory (NOAA/ERL) has initiated an effort to evaluate this model for storm-scale operational systems (Janish, et al. 1995).

Source: Center for Analysis and Prediction of Storms, University of Oklahoma

\section{HOTMAC/RAPAD}

Operational regional/local scale emergency response system for predicting atmospheric releases. Currently the models are used for emergency preparedness applications at Vandenburg Air Force Base (Yamada, 1994). This model has also been tested by a few oversees industrial clients.

Source: Ted Yamada, Yamada Science \& Art Corporation, Los Alamos, NM.

\section{MAS/ADPIC}

Prototype regional scale response system on DEC/ALPHA machines for simulating accidental releases on local scales using regional scale forecasts (Lee, et al., 1994). Mesoscale Atmospheric System (MAS) provides meteorological input for the (APDIC) dispersion model.

Source: Lawrence Livermore National Laboratory, Livermore, CA.

\section{MM4/MM5}

Several groups have developed workstations versions of MM4/5. There are some ongoing efforts to couple this model with air pollution and chemical transport models for assessment studies (Stauffer, et al., 1993).

Source: Pennsylvania State University, University Park, PA.

\section{NORAPS}

The Navy Operational Regional Prediction System (NORAPS) is used operationally to provide forecasts for Naval activities around the globe. A version of this model has been ported to a DEC/ALPHA workstation. LLNL is developing a real-time prognostic emergency response system based on a workstation version of NORAPS and a more advanced ADPIC model (Hodur, 1987).

Source: Naval Research Laboratory, Monterey, CA. 


\section{RAMS}

Real-time mesoscale forecast system for predicting convective storms that can impact launch operations at the Kennedy Space Center (Lyons, et al., 1993).

Source: Mission Research Corp./ASTER Division, Fort Collins, CO.

\section{RAMS/HY-SPLIT.}

Combination of a forecast model (RAMS) and a hybrid Eulerian/Lagrangian pollutant transport model (HY-SPLIT) in a Real-time Environmental Applications and Display sYstem (READY) for predicting dispersion and deposition of hazardous pollutants across international boundaries (Rolph, et al., 1993).

Source: Air Resources Laboratory/NOAA, Silver Spring, MD.

\section{RAMS/LPDM}

Operational semi-prognostic mesoscale atmospheric modeling system for predicting transport and diffusion of tritium releases at the Savannah River Site (Fast, et al. 1993). Source: Savannah River Laboratory, Savannah, GA.

\section{RAMS/UAM-V}

RAMS is used to provide meteorological input to the Urban Airshed Model (UAM-V) to assess the impact of photochemical smog over the coastal and central valley regions of Northern California (Martien and Umeda, 1993).

Source: Bay Air Quality Management District, San Francisco, CA.

The above list is, by no means, exhausive. It nevertheless indicates the high level of modeling activities in the emergency preparedness and response area.

\section{EXAMPLES OF PROGNOSTIC EMERGENCY PREPAREDNESS SIMULATIONS}

In this section we present three prototype simulations that have been performed at LLNL for assessment of potential or real emergency situations. Although the computations were not executed in real-time, we anticipate that, with further advances in numerical algorithms and computational hardware, the tools we have developed can be used for real-time predictions.

\section{A. Flow and Dispersion Around a Building Complex}

A numerical simulation of flow and dispersion around a two-building complex is presented in figures 2 and 3. Figure 2 depicts the steady-state flow field (based on a prescribed $10 \mathrm{~m} / \mathrm{s}$ incident wind) as simulated by FEMTKE, a three dimensional, finite-element-based, NavierStokes model (Lee, 1994). The velocity field is used as input to the dispersion model ADPIC to calculate dispersion and transport of the released pollutants. For illustrative purposes, a point source release was initiated at point $B$ between the two buildings and $4 \mathrm{~m}$ above the ground. The resulting dispersion pattem 5 minutes after the release is shown in figure 3. The particle concentration pattern shows pooling of the pollutants within the low velocity separation zone and 
the subsequent transport of the pollutants up the downwind face of the building into the freestream. A more detail account of this calculation is given in Lee (1994).

\section{B. Simulation of an Accidental Oleum Release}

ARAC recently provided dispersion simulation products to Califomia state and local . emergency and health service agencies during and after the accidental venting of a chemical tank car in Richmond, CA (Baskett, et al., 1993). About 8 tons of oleum, $\mathrm{SO}_{3}$, were released over 4 hours beginning at about $7 \mathrm{AM}$ on July 26,1993 . A visible cloud containing sulfuric acid, $\mathrm{H}_{2} \mathrm{SO}_{4}$, formed in the cool, moist early morning air was dispersed by the ambient winds over a path almost a kilometer wide and several kilometers long. . Thousands of people reported to local hospitals complaining of irritation of their eyes, skin and respiratory tract.

As part of our effort to evaluate the feasibility of developing a prognostic response system, we have simulated the dispersion of the toxic release that initiated from the tank car. We calculated gridded winds over the San Francisco Bay Area and employed these winds as input to the dispersion model ADPIC. The prognostic model MAS (Mesoscale Atmospheric System), developed jointly at LLNL and the University of California at Davis (Kim and Soong, 1994), was used to predict the meteorological fields during the accident. MAS is a primitive equation, regional scale, model based on the sigma coordinate system and contains a boundary layer parameterization, cloud microphysics, radiative transfer, surface energy balance and a two-layer soil model. A $5 \mathrm{~km}$ resolution $85 \times 89$ mesh with 14 graded vertical layers was used within a $425 \mathrm{~km} \times 445 \mathrm{~km}$ computational domain. Initial and boundary conditions for the calculation were interpolated from the $80 \mathrm{~km}$ resolution gridded analyses that were supplied by the National Weather Service's ETA model. The ETA model is one of several operational limited-area models that provide meteorological forecasts fields at $12 \mathrm{hr}$ intervals over North America. The MAS simulation began approximately $14 \mathrm{hrs}$ before the accident and continued for $10 \mathrm{hrs}$ after the accident. Figure 4 show the wind at the lowest layer (125 m AGL) within a $259 \mathrm{~m} \times 300$ $\mathrm{km}$ window centered at Richmond after $12 \mathrm{hrs}$ of integration. The wind pattern, which is representative of the winds at the time of the accident, clearly shows a northeasterly direction that generally agreed with the drift direction of the toxic cloud.

For comparison purposes we calculated the gridded wind fields using two approaches, one used our operational diagnostic wind field model MATHEW, the other used the prognostic model MAS as discussed earlier. The wind field generated from each approach was used to drive the dispersion model, ADPIC. The domain for the dispersion computation is significantly smaller, being $25 \mathrm{~km} \times 25 \mathrm{~km} \times 700 \mathrm{~m}$ with a grid resolution of $1 \mathrm{~km} \times 1 \mathrm{~km} \times 50 \mathrm{~m}$. Figure 5 depicts the prognosed (100 m height) wind field at approximately 45 mins after the accident and the ADPIC-generated dispersion pattern after 2 hours. This pattern and others (not shown) compare favorably with similar results from the operational diagnostic calculations that were obtained in real-time during the accident. It is important to note that, in contrast to our diagnostic simulation, the prognostic calculations did not require the ingestion of any local wind data to generate the correct winds for the dispersion model. 


\section{Quantitative Precipitation Forecasts for Flood Emergencies}

The winter storms of 1994-95 resulted in severe flooding in many parts of the U. S. as well as countries throughout Europe. There is a critical need for forecasting tools that are more effective in alerting and updating the population within the storm areas well ahead of time. Current meteorological forecast models contain inadequate information for use in hydrological models that predict flood conditions. For example, watershed models are driven by very local precipitation and snow information that is poorly prognosed by meteorological models which calculate on coarse grid resolutions. Clearly, quantitative forecasts of localized flooding must be generated from models operating on small but highly-resolved domains that focus exclusively on the areas most prone to floods.

The MAS model, computing on a grid resolution of $20 \mathrm{~km}$, is used to generate local precipitation patterns for input into the LLNL-developed Coupled Atmospheric-Riverflow Simulation (CARS) system. The riverflow model is capable of telescoping meteorological information down to the scale of individual watersheds. The MAS/CARS models successfully predicted the rainfall and riverflow conditions over the Russian River Basin of Northern California during the first 12 days of January 1995, particularly during the period when heavy rains caused severe flooding. Figure 6 shows a snapshot of the wind forecast and the accumulated $6 \mathrm{hr}$ total precipitation (rain and snow) forecast on January 9, 1995. The simulated riverflow during this storm period was within $20 \%$ of the observed flow during the flood stage.

\section{CONCLUSIONS}

Advances in high-performance workstation technology, in conjunction with the building of the information superhighway, have paved the way for computational fluid dynamics to be readily integrated into locally-based emergency preparedness and response modeling systems. Many groups have already developed these systems for operational use and are beginning to test them in real-time situations. The future applications of these modeling systems will be expanded to include both health-threatening as well as weather-related emergencies.

\section{ACKNOWLEDGEMENTS}

This work was performed under the auspices of the Department of Energy by the Lawrence Livermore National Laboratory under Contract No. W-7405-Eng-48. The principal author wishes to thank Dr. Su-Tzai Soong and Xiaorong Yin of U. C. Davis for assistence in simulating the Richmond wind fields with the MAS model.

\section{REFERENCES}

Baskett, R. L., P. J. Vogt, W. W. Schalk, III, B. M. Pobanz, C. S. Foster, J. S. Ellis, 1995: The Challenge of Emergency Response on the MESO-Gamma Urban Scale: A Case Study of the July 26, 1993 Oleum Tank Car Spill in Richmond, CA. Proc. of the Fifth Topical Meeting on Emergency Preparedness and Response, Savannah, GA, Apr. 18-21, 1995, AMS. 
Fast, J. D., B. L. O'Steen, R. P. Addis, 1993: Operational Mesoscale Atmospheric Modeling at the Savannah River Site, Proc. of the Topical Meeting in Environmental Transport and Dosimetry, Charlotte, NC, Sept. 1-3, 1993, AMS.

Hodur, R. M., 1987: Evaluation of a Regional Model with an Update Cycle, Mon. Wea. Rev., $115,2707-2718$.

Janish, P. R., K. K. Droegemeier, M. Xue, K. Brewster and J. Levit, 1995: Evaluation of the Advanced Regional Prediction System (ARPS) for Storm-scale Operational Forecasting. Proc. of the 14th Conf. on Weather Analysis and Forecasting, Dallas, TX, Jan. 15-20, 1995, AMS.

Kamada, R. F., 1992: An evaluation of Diagnostic Atmospheric Dispersion Models for "Coldspill" Applications at Vandenberg Air Force Base, CA. Naval Postgraduate School Report NPS-PH-93-05.

Kim, J., S. T. Soong, 1994: Simulation of a Precipitation Event in the Western United States. Proc. of the Sixth Conf. on Climate Variations, Nashville, TN, Jan. 23-28, 1994, AMS.

Martien, P., T. Umeda, 1993: Photochemical Model Sensitivity Tests on the Effects of Utility Boiler $\mathrm{NO}_{\mathrm{x}}$ Controls on Ambient Ozone Concentrations. Bay Area Air Quality Management District Technical Memo, TM 93001.

Lee, R. L., 1994: Numerical Modeling of Three-dimensional Flow and Pollutant Dispersion Around Structures. Environmental Software, 9, 175-187.

Lyons, W. A., R. A. Pielke, M. Uliasz, C. J. Tremback, R. L. Walko, 1993: New Technologies for Modeling Mesoscale Transport and Diffusion in Coastal Zones and Complex Terrain. Proc. of the Topical Meeting in Environmental Transport and Dosimetry, Charlotte, NC, Sept. 1-3, 1993, AMS.

Rolph, G., J. McQueen, R. Draxler, 1993: Real-time Environmental Applications and Display sYstrem (READY). Proc. of the Topical Meeting in Environmental Transport and Dosimetry, Charlotte, NC, Sept. 1-3, 1993, AMS.

Stauffer, D. R., N. L. Seaman. T. T. Wamer and A. M. Lario, 1993: Application of an Atmospheric Simulation Model to Diagnose Air-pollution Transport in the Grand Canyon region of Arizona. Chem. Eng. Comm. 121, 9-25.

Sullivan, T. J., C. S. Foster, K. T. Foster, R. L. Baskett, J. S. Nasstrom, W. W. Schalk, III, Atmospheric Release Advisory Capability: Real-time Modeling of Airborne Hazardous Materials. Bull. Amer. Meteor. Soc., 74, 2343 (1993). 
Yamada, T., 1994: Three-dimensional Forecast Models for Emergency Response Management. 1994 JANNAF Safety and Environmental Protection Subcommittee Meeting, Aug. 1-4, 1994. San Diego, CA, Chem. Propulsion Info. Agency, Pub. 614, v. 1.

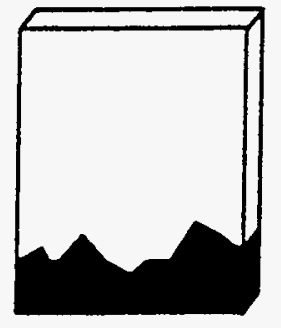

TOPOG

Creates undertying topographic grid
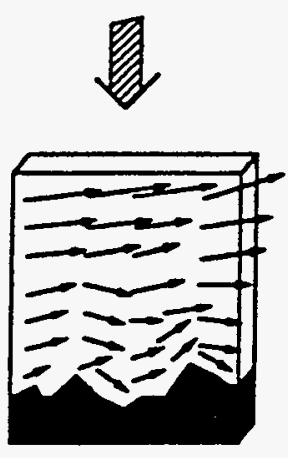

MATHEW Adjusts winds to bo mass consistent
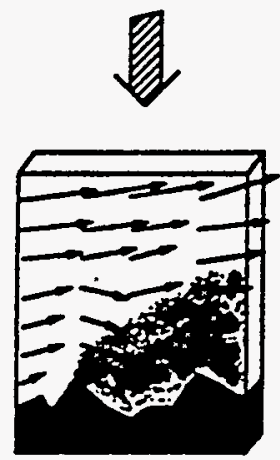

ADPIC

Advocts and diffuses sources over grid using the particle-in-cell method
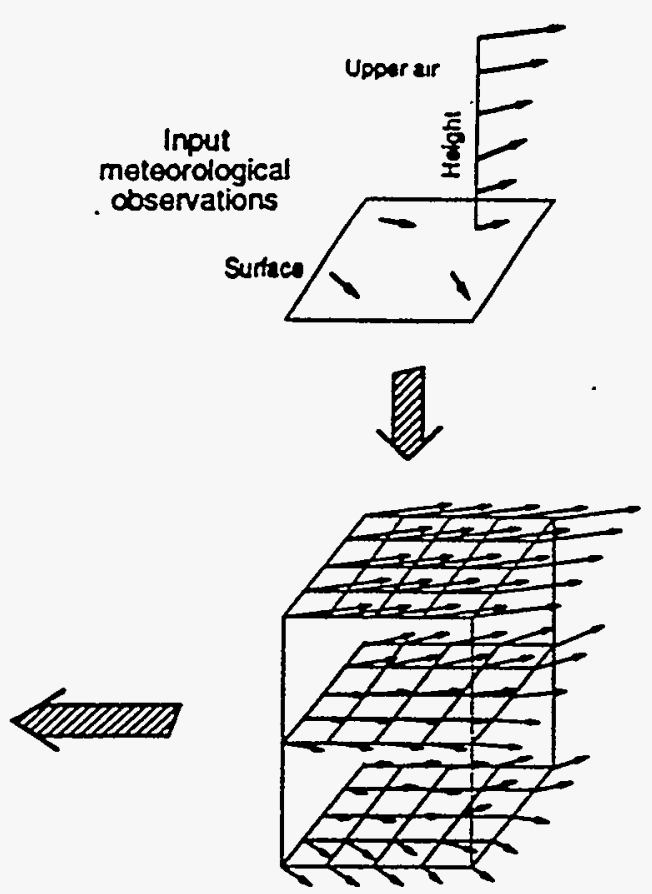

MEDIC

Interpolates obsegvations to 3-0 grid using $1 / r^{2}$ weighting
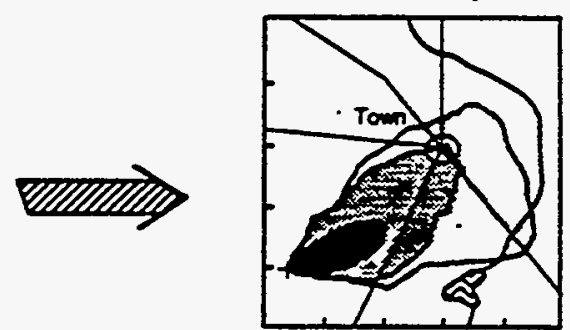

PLOT CONTOUR

Creates isopleth maps showing the extent of the hazard

Figure 1. The Atmospheric Release Advisory Capability (ARAC) Modeling System 

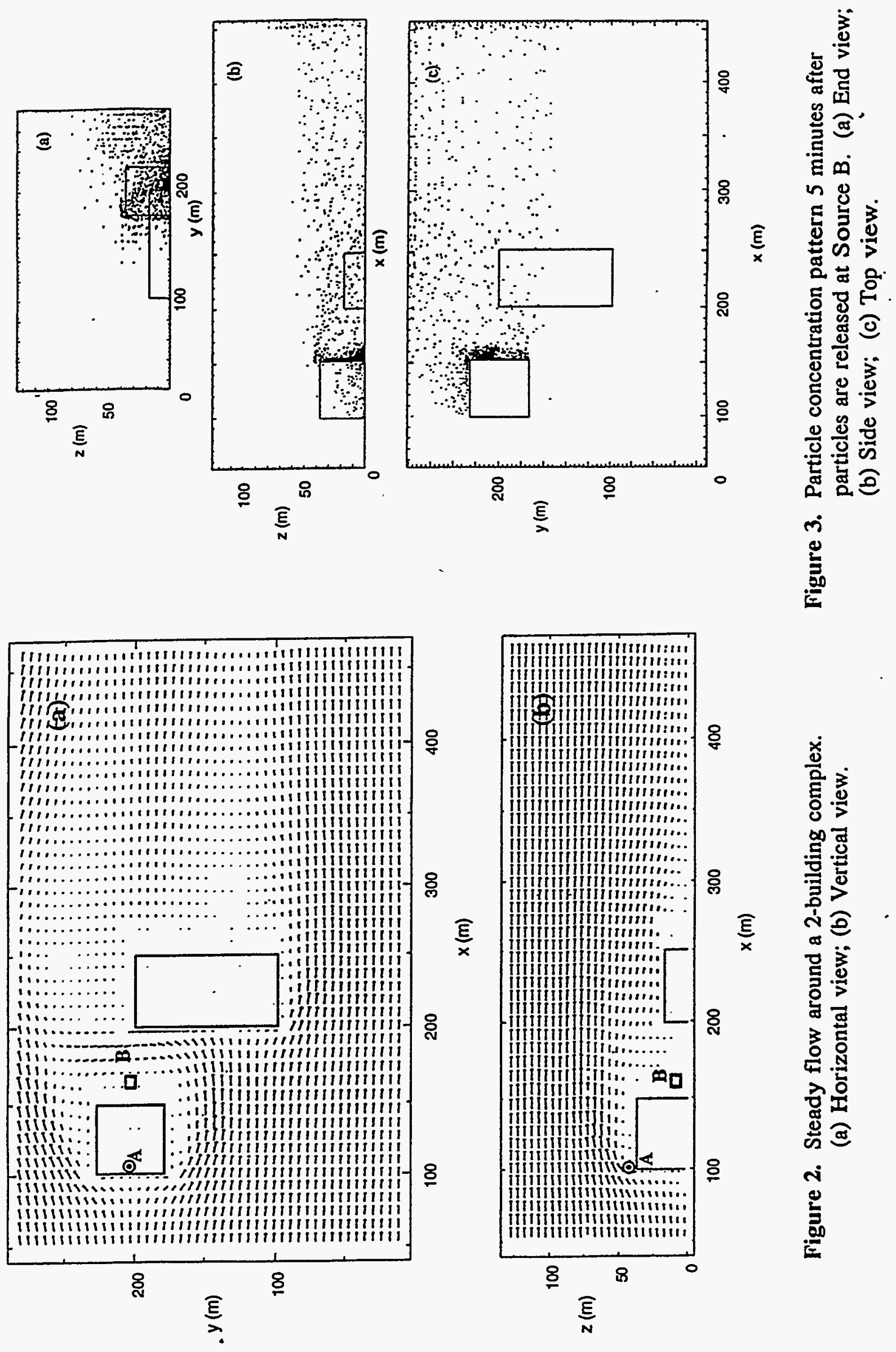


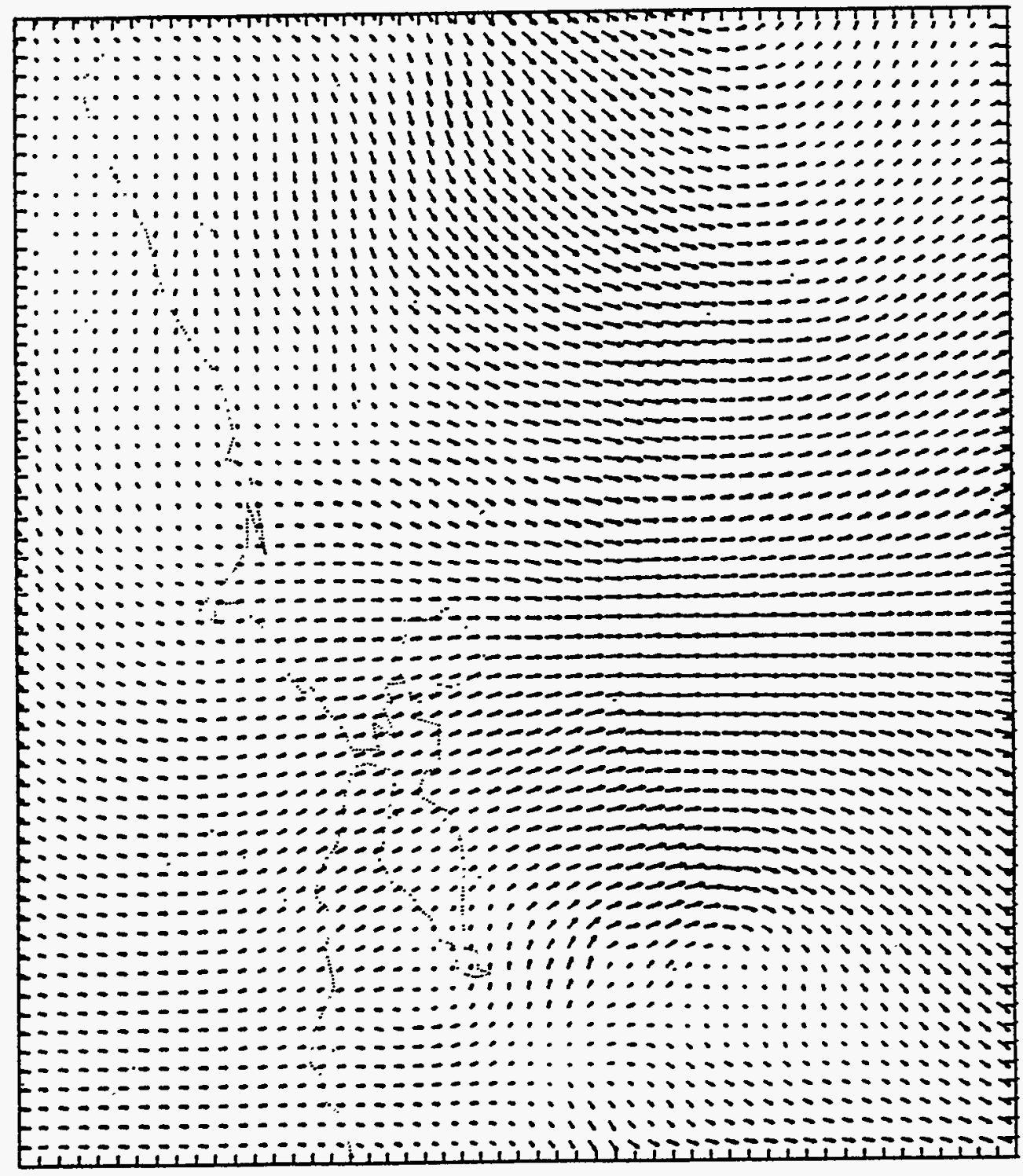

Figure 4. Predicted regional wind pattern at $125 \mathrm{~m}$ above ground near the time of the accidental spill. 

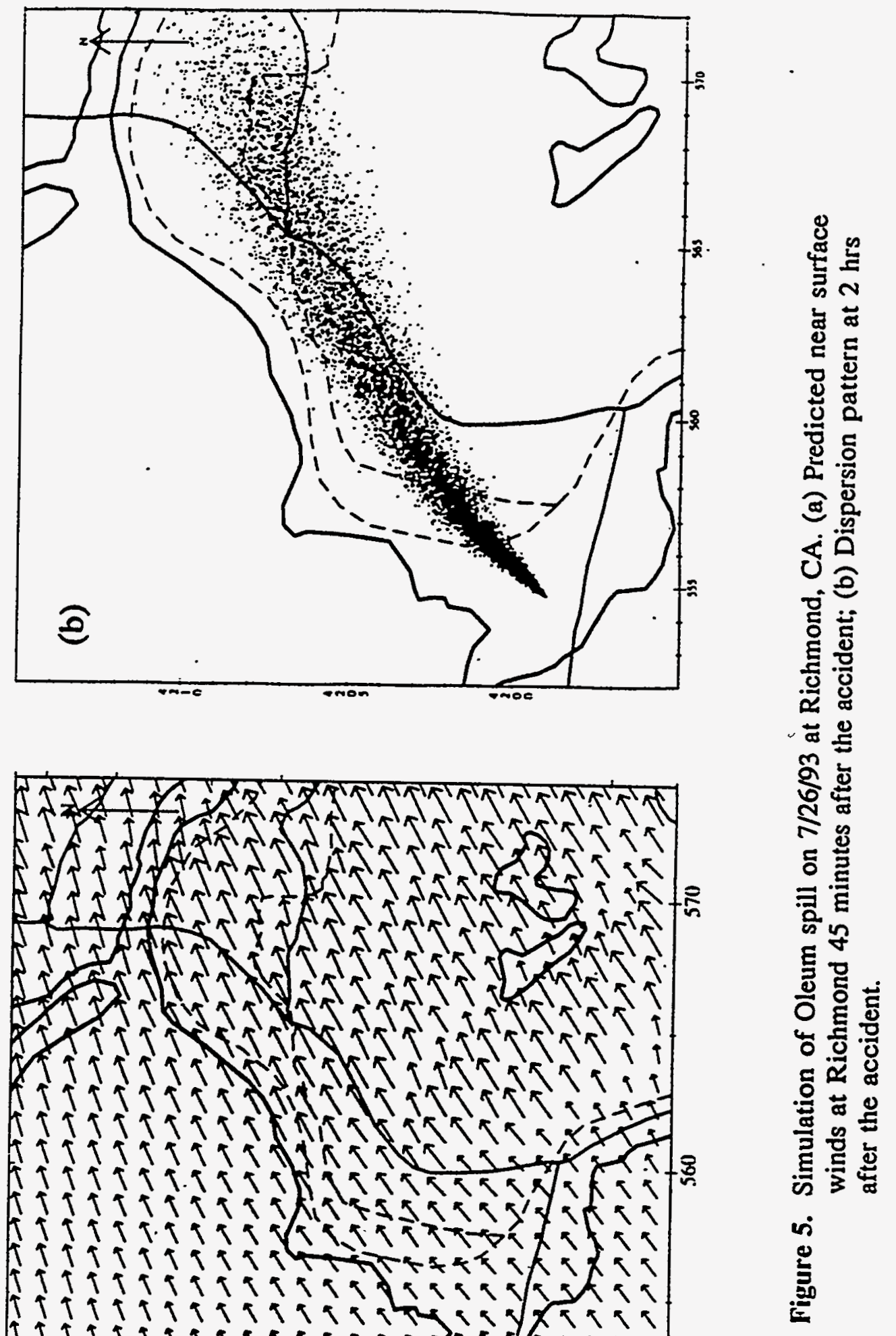


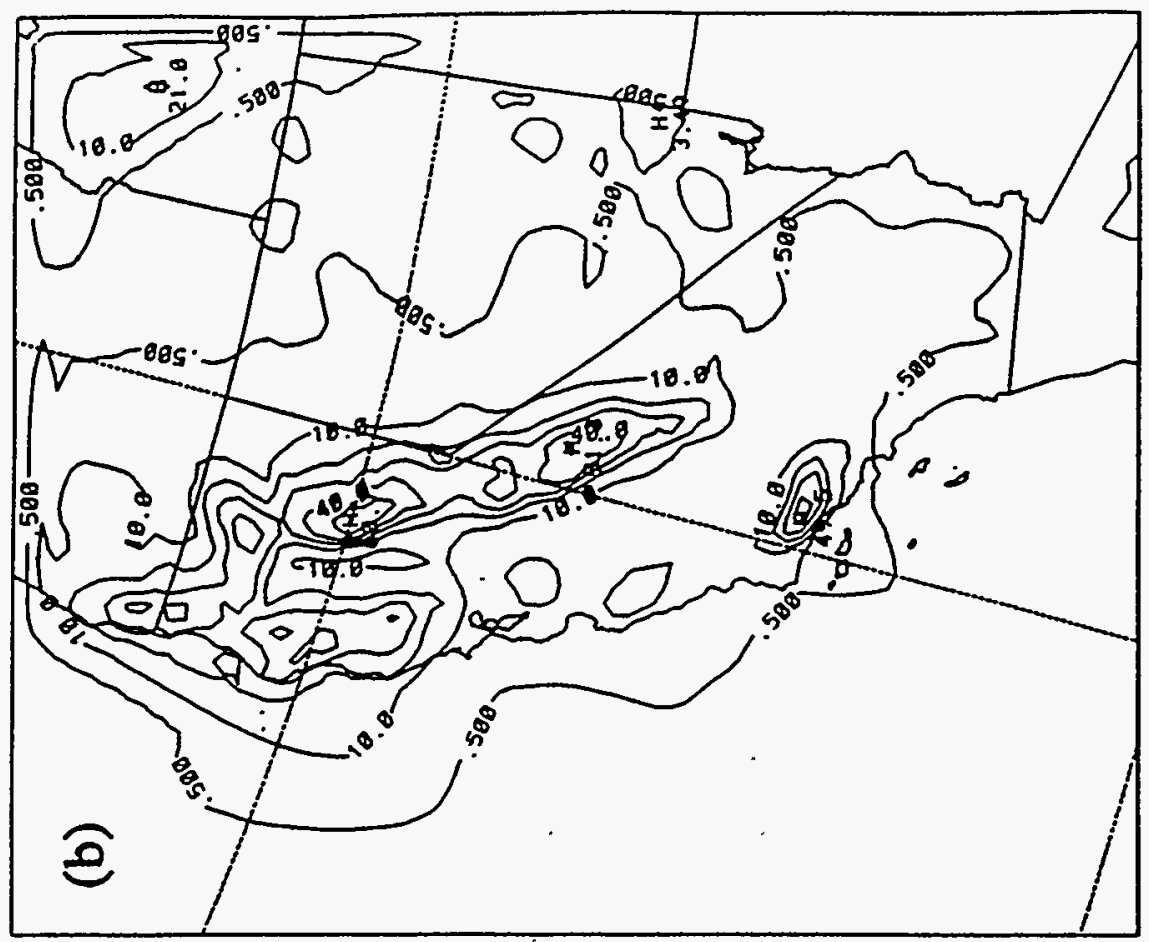

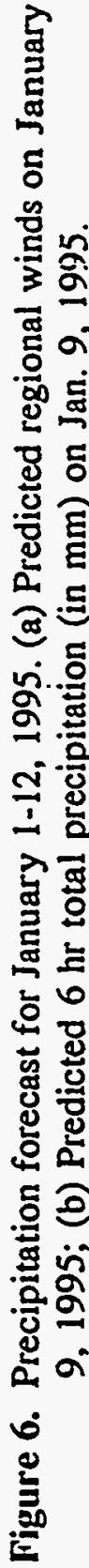

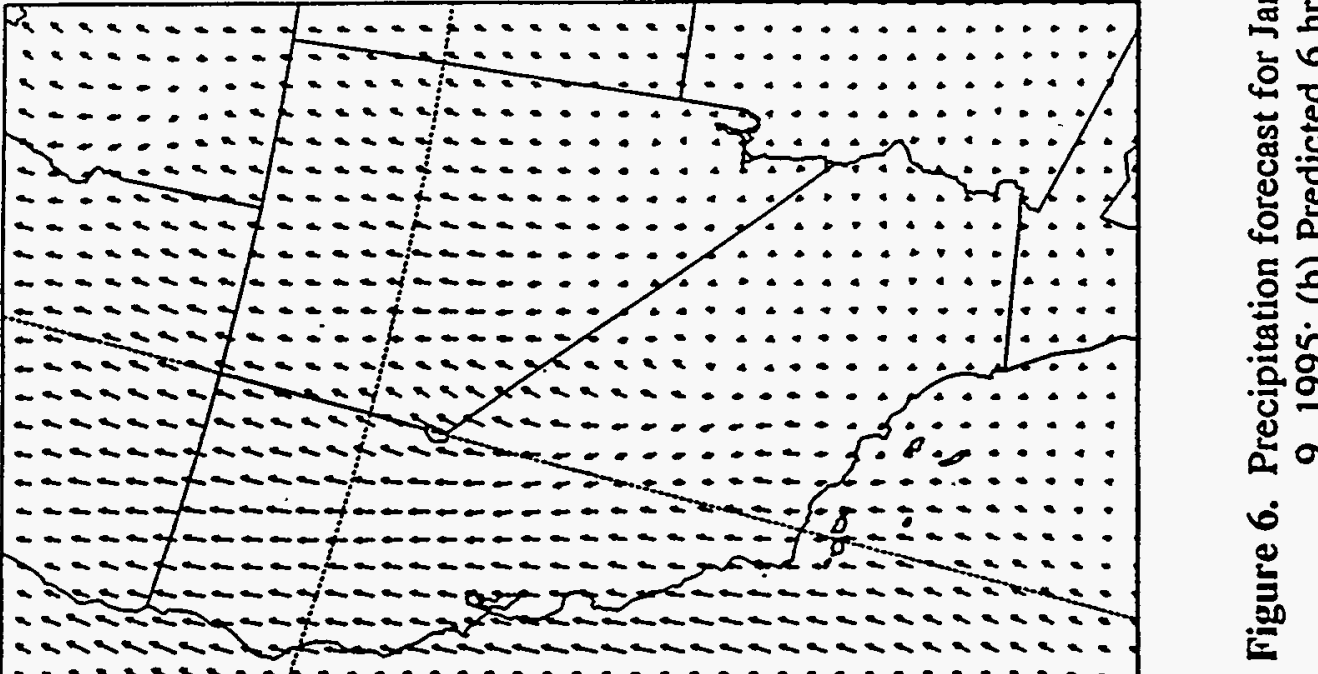

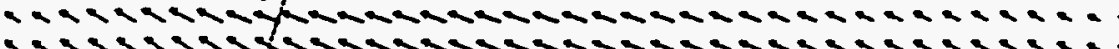

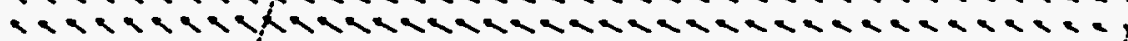

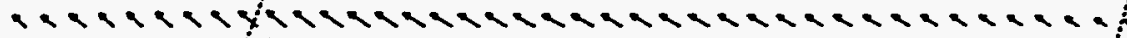

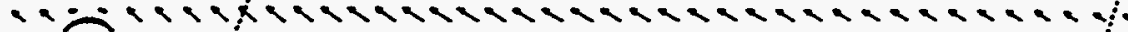

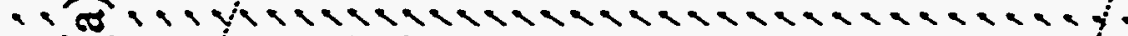

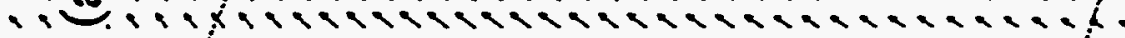
: 1 : 
